\title{
Single-plant chambers to control humidity for pathological studies
}

\author{
D. R. BUTLER, R. K. REDDY and K. D. R. WADIA \\ Resource Management Program, International Crops Research Institute for the Semi-Arid Tropics \\ (ICRISAT), Patancheru PO. Andhra Pradesh 502 324, India
}

The construction of a set of controlled-humidity chambers for single plants is described. Accurate control of relative humidity (r.h.) between $40 \%$ and $99 \%$ was achieved by mixing dry air with a saturated air stream using solenoid valves controlled by a programmable data logger. At values of r.h. $>90 \%$, mean values over periods greater than $1 \mathrm{~min}$ were constant to within $\pm 0.1 \%$ and spot measurements at $3 \mathrm{~s}$ intervals were within $0.3 \%$ of the mean value. The system responded to a step change of r.h. in about 6-10 min and diurnal changes of r.h. were reproduced, similar to those observed in nature. The stability of control made it possible to differentiate between the requirement of liquid water and very high humidity $(98 \%$ r.h.) for conidial germination and subsequent infection of groundnut by Phaeoisariopsis personata, the cause of late leaf spot disease.

\section{INTRODUCTION}

Humidity is a key weather variable which strongly influences the majority of foliar pathogens. With the exception of powdery mildews, spores of many foliar fungal pathogens require liquid water to germinate, although a number of species have been reported to germinate when the air is not saturated (Yarwood, 1978). However, because of the difficulty in avoiding transient condensation in controlled conditions when the air is near saturation, Schein (1964) questioned the validity of many of these reports. While agreeing in general with Schein's view, we consider the careful experimentation by Clayton (1942) to be an exception. He was able to distinguish pathogens in vitro which germinated on a dry surface at relative humidities of $99 \%$ and above (e.g. Venturia inaequalis) from those which require liquid water (e.g. Sclerotinia fructicola).

Harrison (1992) pointed out that humidity within the leaf boundary layer is usually different from the surrounding air and is dependent on wind speed. He discounted numerous reports of the minimum relative humidity (r.h.) for sporulation of Phytophthora infestans on potato because they did not refer to humidity in the zone where sporangia would be formed.

Accurate control of humidity is difficult, especially in situations where plants are transpiring. Saturated salt solutions provide a convenient method to control r.h. in vitro (O'Brien, 1948), but when living plant material is introduced into such a system the equilibrium humidity changes. Fungi commonly respond to relative humidity between $90 \%$ and $100 \%$ and fluctuations in temperature must be kept to a minimum to achieve good control in this range. For example, with a constant vapour pressure at $25^{\circ} \mathrm{C}$ and $98 \%$ r.h., a $0.2 \mathrm{~K}$ change in temperature will alter the r.h. by $1.2 \%$. Harrison \& Lowe (1989) described systems to control r.h. for detached leaves and whole plants using water baths to control the dewpoint and chamber temperatures. In their plant chamber, they were able to obtain r.h. within $\pm 2 \%$ of the desired value in studies on sporulation of $P$. infestans.

Because of the difficulty in controlling humidity, relatively few studies on the effect of humidity on pathogen processes on living plants have been reported. Most reports describe the effect of different levels of constant humidity on processes such as sporulation and infection. In nature, diurnal changes in humidity can be large and little is known of the response of pathogens to a dynamic situation.

A set of controlled-humidity plant chambers has been designed for plant pathological studies. The chambers can be controlled individually to cater for experiments with up to six treatments and they can be programmed to give diurnal changes in humidity. 


\section{DESCRIPTION}

\section{The room}

The chambers are housed in a basement room (below ground level) where the diurnal temperature changes by about $0.7 \mathbf{K}$ between day and night. The natural mean temperature varies from $23 \mathrm{C}$ in winter to $29 \mathrm{C}$ in summer, but the temperature can be maintained below $27 \mathrm{C}$ by operating an evaporative cooler when necessary. The cooler, which draws dry air through wet mats, is positioned outside the room and cool air enters the room through a duct. When in use. the cooler runs constantly and so does not affect the daily range or cause short-term temperature fluctuations.

The room was lit by two $36 \mathrm{~W}$ fluorescent tubes and the irradiance in the chambers was about $2 \mu \mathrm{mol} \mathrm{m}^{2}$. $\mathrm{s}$.

\section{The chambers}

The plant chambers were arranged on a flat surface covered with laminated plastic.

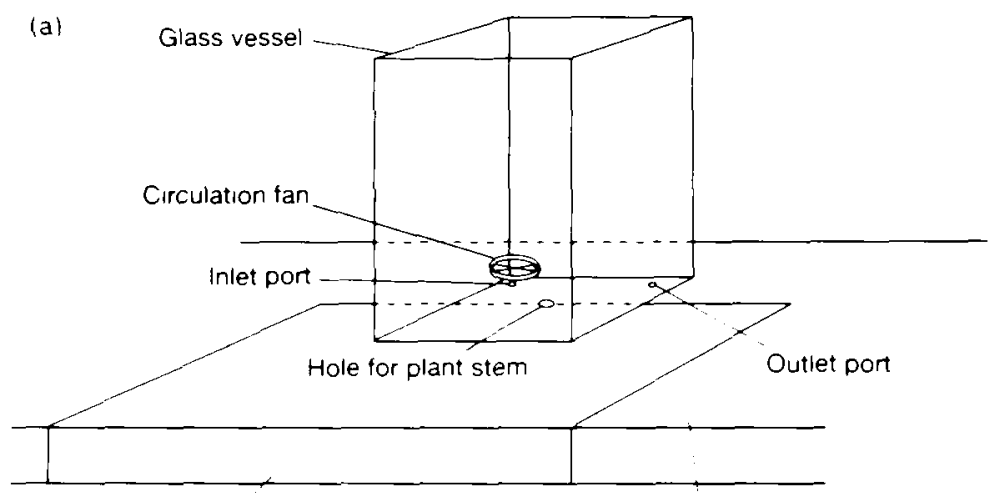

Removable portion

Working surface

(lamınated plastıc)

(b)

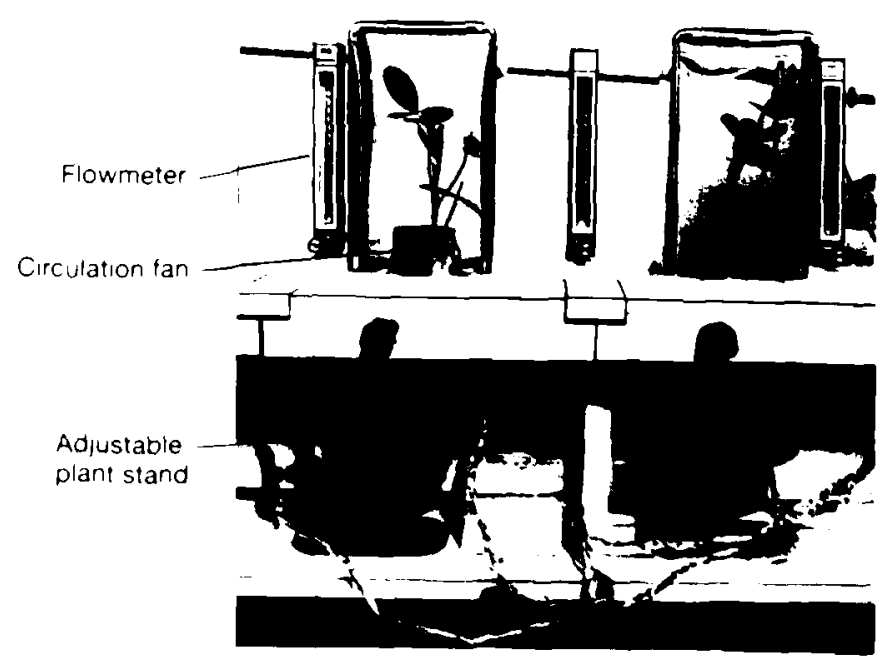

Fik. I. J ).

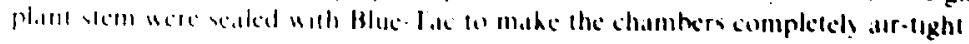


Removable portions allowed plants to be introduced and the base of each plant stem was sealed to the working surface (Fig. 1). Glass chambers, made from 15 (length) $\times 13$ (width) $\times$ 24 (height) cm storage vessels were inverted and sealed to the surface. The sealing material was Blue-Tac (Bostik Ltd, Leicester, UK).

Each chamber was supplied with moist and dry air, mixed in an appropriate ratio to achieve the desired humidity and, before entering the plant chamber, these two air streams passed through a $350-\mathrm{ml}$ glass mixing vessel. The vapour pressure of air leaving the chamber was measured so that water vapour added to the chamber air by transpiration was accounted for in determining the amount of dry air supplied to the mixing vessel.

The air flow system is shown in Fig. 2. Compressed air was supplied to the system through a pressure regulator set to $172 \mathrm{kPa}$. The air flow was then divided before conditioning for the moist and dry air lines. The supply to each line was regulated by a main valve.

Moist air was supplied continuously to each mixing vessel with a flow rate between 0.5 and $0.7 \mathrm{l} / \mathrm{min}$. The air was humidified by bubbling through distilled water in a flask submerged in a water bath. The water bath temperature was maintained about $3 \mathrm{~K}$ greater than the chamber temperatures by switching on the heater only when the water bath temperature fell below the required value. Air from the humidifier passed through a heated tube to the moist air line, which was housed in a heated box to prevent condensation. Both the tube and the box were controlled to about $5 \mathrm{~K}$ greater than the chamber temperatures. Chamber temperatures were not controlled, but reached a value close to the air temperature of the room (usually about $26^{\circ} \mathrm{C}$ ). The temperature in each chamber was measured using five copper/constantan thermocouples in series, referenced to a thermistor in an insulated oil bath. This provided a resolution of $0.01^{\circ} \mathrm{C}$ and the effect of electrical interference on readings was less than $0.05^{\circ} \mathrm{C}$.

The dry air supply passed through a container of silica gel before entering the dry air line. Dry air was supplied to each mixing vessel through a solenoid valve and a flow meter where the flow rate could be adjusted independently (for each chamber).

The outlet from each chamber passed over a humidity sensor in the heated box before venting to the atmosphere. Air in the chamber was mixed and circulated with a fan immediately above the inlet port. This reduced the leaf aerodynamic resistance to an average value of $20 \mathrm{~s} / \mathrm{m}$ (estimated from the evaporation rate using filter paper leaf replicas). This value implies an average leaf boundary layer thickness of $0.5 \mathrm{~mm}$ which would normally be associated with wind speeds in the field greater than $3 \mathrm{~m} / \mathrm{s}$. The vapour pressure within the boundary layer of a

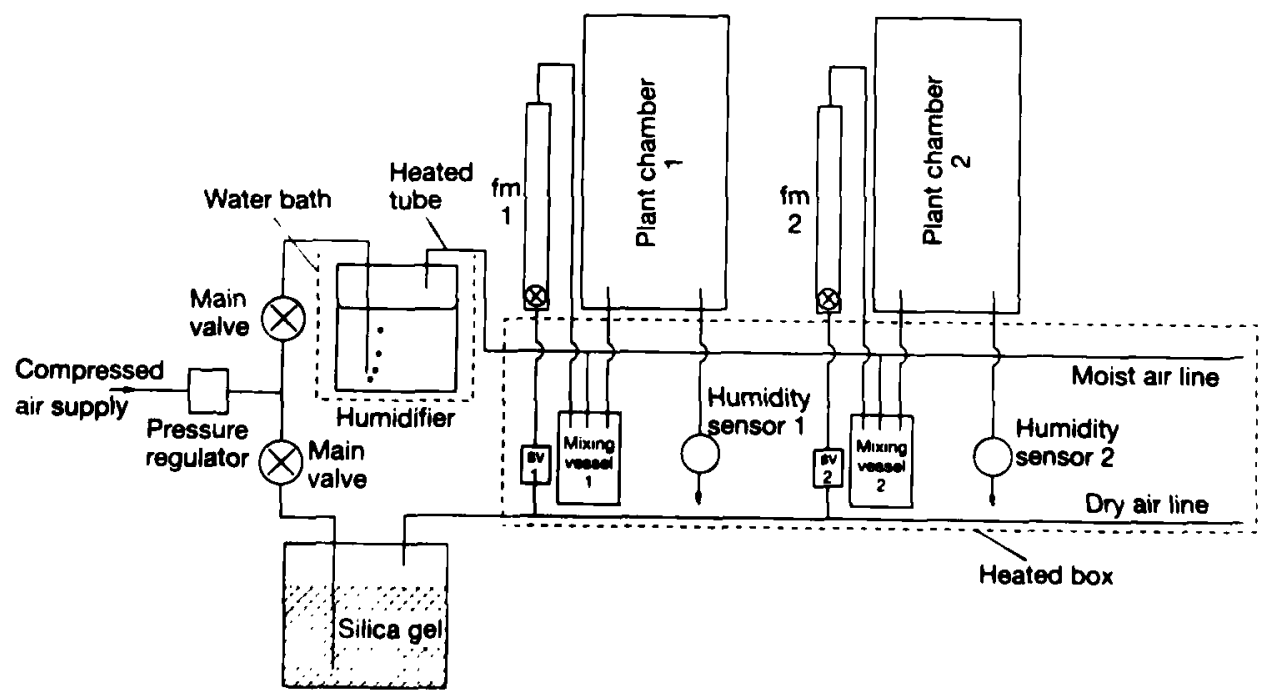

Fig. 2. The air flow system for humidity control. For clarity. two out of a total six plant chambers are shown. Abbreviations: $\mathrm{sv}=$ solenoid valve; $\mathrm{fm}=$ flowmeter. 
transpiring leaf will be greater than the surrounding air, but the difference between the two is reduced as the boundary layer thickness is reduced.

\section{Humidity control}

Relative humidity in the plant chambers was calculated from the chamber temperature and the absolute humidity of air leaving the chamber. Air humidity was measured either with a condensation dew-point meter (General Eastern, Woburn, MA, USA) or with a thin-film capacitative Humicap sensor (Vaisala Sensor Systems, Helsinki, Finland). In either case, vapour pressure of the chamber air was calculated, either directly from the dew-point temperature using an algorithm by Lowe (1976), or from r.h. and the Humicap sensor temperature. Relative humidity in the chamber was obtained from the ratio between air vapour pressure and saturated vapour pressure at chamber temperature. As the Humicap sensors were located in the heated box ( $5 \mathrm{~K}$ greater than chamber temperature), their r.h. readings never exceeded $80 \%$, and errors associated with thin-film capacitative sensors at larger r.h. values were avoided. All the Humicap sensors were calibrated by comparing the computed chamber r.h. with that from a dew-point meter.
Outputs from the chamber temperature and humidity sensors were recorded every $3 \mathrm{~s}$ with a programmable data logger (Model 21X, Campbell Ltd, Logan, UT, USA). Proportional humidity control was achieved by using the data logger to vary the length of the activation pulse to each solenoid valve when the chamber r.h. was within $\pm 1 \%$ of the set value. If the chamber r.h. exceeded the set value by more than $1 \%$, dry air supply was continuous and, if the chamber r.h. was more than $1 \%$ below the set value, the solenoid valve was switched off.

Set values of r.h. could be programmed for each chamber independently and could be constant, or vary with time, using functions to simulate natural diurnal changes of r.h. The number of functions used simultaneously was limited by the memory size in the data logger. This could be overcome by using two data loggers, each one to control three chambers.

\section{PERFORMANCE}

Over short periods the chamber temperature was very stable, with spot readings remaining within $\pm 0.03 \mathrm{~K}$ of the mean over $30 \mathrm{~min}$ (Fig. 3). The example in Fig. 3 shows the frequency distribution of temperature when the mean value was $26.17 \mathrm{C}$, and spot readings were grouped in intervals of $0.01^{\circ} \mathrm{C}$. As temperature is central to

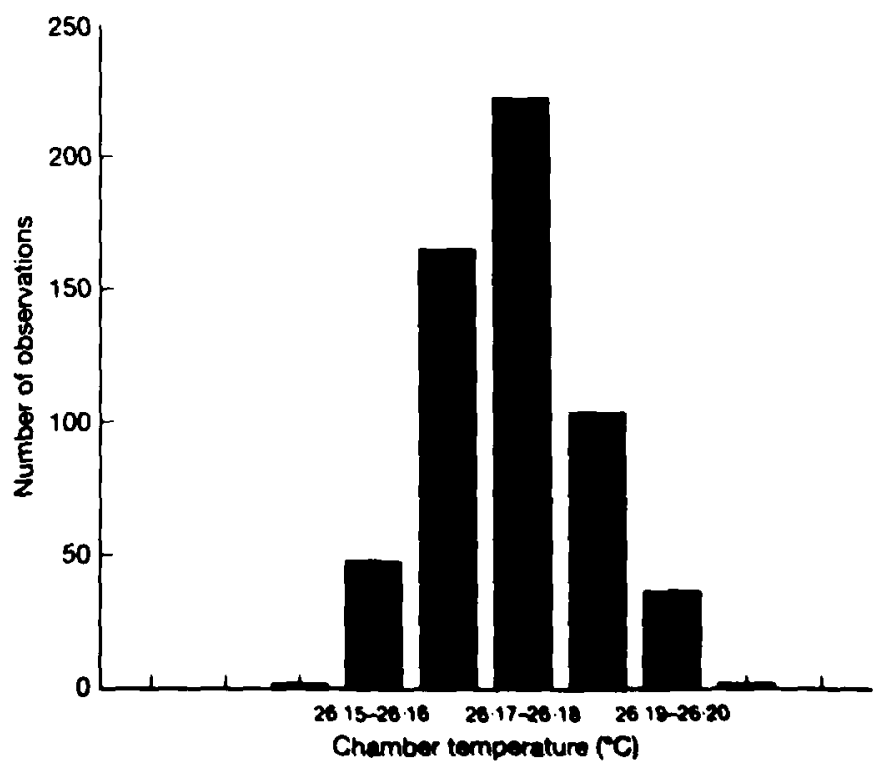

Fig. 3. The frequency distribution of spot reading, of chamber temperuture made al 3-s intervals over a $30 \mathrm{~min}$ period 
the determination of r.h., this provided a good basis for humidity control.

With a dry air flow rate of $31 / \mathrm{min}$, it was possible to obtain a stable r.h. value anywhere in the range from 40 to $99 \%$. Usually the equilibrium value was slightly different from the set value, but the deviation was always within $\pm 1 \%$ r.h. The extent of short-term fluctuations in r.h. varied with the set value, and became smaller as r.h. increased. For example, with a set value of $96 \%$ (Fig. $4 a$ ), the measured mean was $96.3 \%$ r.h. and spot readings ranged between 96.0 and $96.7 \%$ r.h., whereas with a set value of $50 \%$ r.h. (Fig. 4b), the measured mean was $50.4 \%$ and spot readings ranged between 49.8 and $51.0 \%$. The small short-term fluctuations close to saturation provided the capability of achieving 'high humidity' (say $98 \%$ r.h.), while avoiding transient condensation on the leaves. With a mean value of $98 \%$ r.h., "instantaneous" values would range from $97.7 \%$ to $98.3 \%$, remaining more than $1 \%$ r.h. below saturation. This reasoning is supported by the observation that condensation was never observed on the

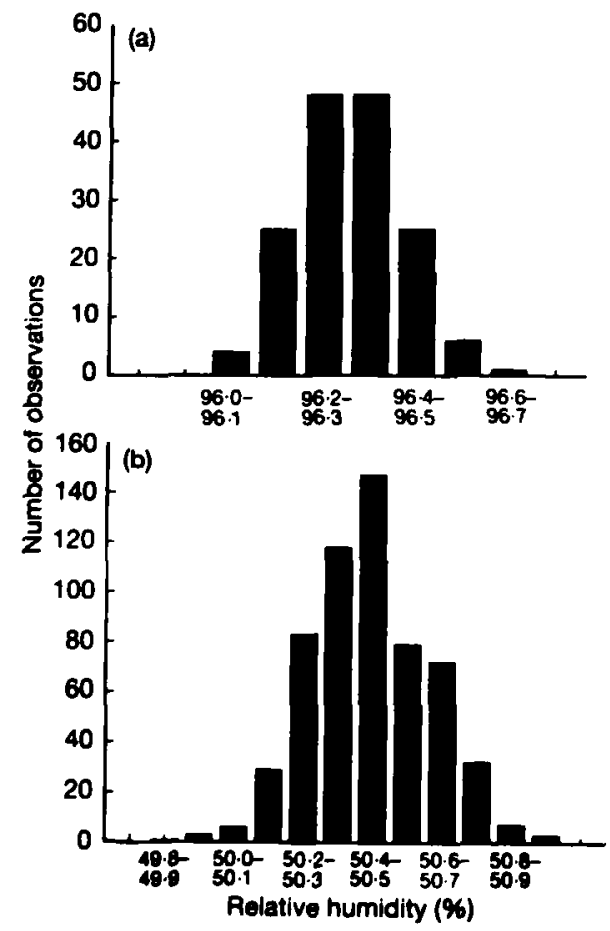

Fig. 4. The frequency distribution of spot readings of relative humidity made at $3-\mathrm{s}$ intervals; (a) with a set humidity of $96 \%$ r.h. and (b) with a set humidity of S0\% r.h.

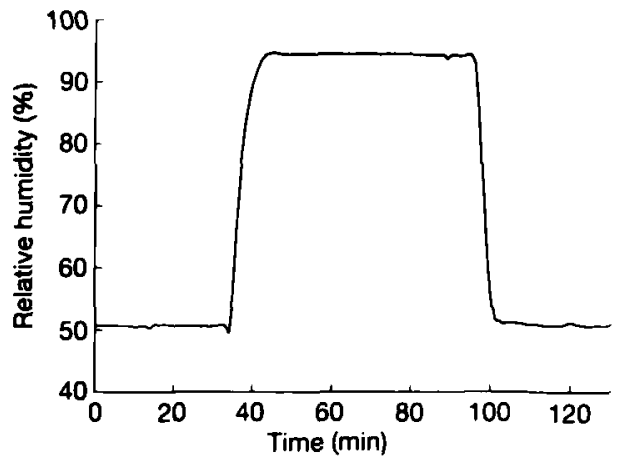

Fig. 5. One-minute average r.h. values with step changes in the set r.h. The set value was switched from $50 \%$ to $95 \%$ and back to $50 \%$.

chamber wall with a set value of $98 \%$ r.h. Slight condensation became noticeable at settings of $99 \%$ r.h. and above.

The response of the system to a step change in r.h. is shown in Fig. 5. Starting from $50 \%$ r.h., an increase of nearly $45 \%$ r.h. took about $10 \mathrm{~min}$ compared with about $6 \mathrm{~min}$ for a decrease of $45 \%$. The system can also be programmed with a sine function to generate diurnal changes in r.h. (see, for example, Fig. 6).

\section{INITIAL EXPERIMENTS}

The plant chambers were used to examine how surface wetness and/or high r.h. affect infection of groundnut by Phaeoisariopsis personata, the causal agent of late leaf spot disease.

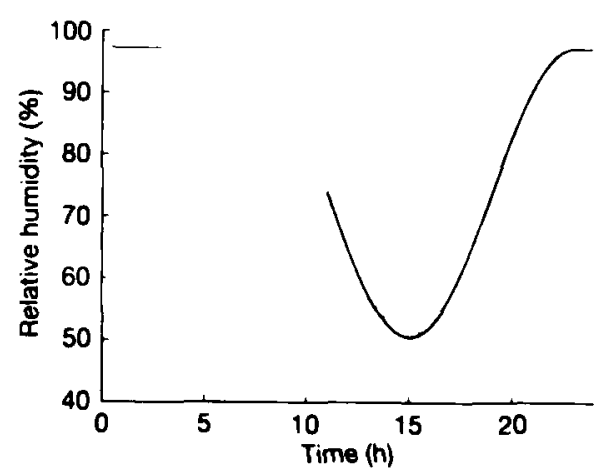

Fig. 6. One-minute average r.h. values with a sine function to simulate a diurnal curve. The data logger was programmed with the equation: $r$.h. $24(\sin (\pi((1+1) / 8-0.5)))$ between 07:00 and 23:00 hours, where $t$ is the time in hours. Al other times the set value was $98 \%$ r.h. 


\section{Methods}

Two experiments were carried out on the groundnut cultivar TMV 2, which is susceptible to late leaf spot disease. Potted plants were raised in a glasshouse using a potting medium of $50 \%$ loam, $25 \%$ sand and $25 \%$ compost. The medium was steam-sterilized and the plants were fed with Broughton's nutrient solution (Broughton \& Dilworth, 1971). Four-week-old plants (one per pot) were used for experiments. Conidia were multiplied by inoculating groundnut leaves (cv. TMV 2) with isolates derived from locally collected conidia using the method described by Wadia \& Butler (1994a). The inoculum was harvested with a cyclone spore collector and stored at $4 \mathrm{C}$.

The first experiment was to determine whether leaf wetness is necessary for $P$. persanata infection. Dry inoculum was prepared by adding approximately $5 \mathrm{mg}$ of conidia to $5 \mathrm{~g}$ of talcum powder and thoroughly mixing with a magnetic stirrer. The powder was applied to leaves through a muslin cloth, ensuring that both leaf surfaces were uniformly coated. Lannou \& Blizoua Bi (1989) successfully used a similar dry inoculation method for $P$. personata. The number of conidia per unit leaf area was not determined.

One plant was assigned to each of four treatments (Table 1). Depending on the treatment, a dew chamber (Butler et al., 1994) set to $23 \mathrm{C}$ was used to provide leaf wetness immediately after inoculation. The treatments were as follows:

Treatment 1 (control): put into the dew chamber for 5 nights ( $16 \mathrm{~h}$ each night) and moved to a plant growth room at $26 \mathrm{C}$, about $70 \%$ r.h. and an irradiance of approximately $200 \mu \mathrm{mol} / \mathrm{m}^{2}$.s for $8 \mathrm{~h}$ each day.

Treatment 2: put into the dew chamber for $16 \mathrm{~h}$ and then moved to a controlled humidity chamber for 4 days with $16 \mathrm{~h}$ at $95 \%$ r.h. and $8 \mathrm{~h}$ at $70 \%$ r.h. each day.

Treatment 3: put into the dew chamber for $16 \mathrm{~h}$ and then moved to a controlled humidity chamber for 4 days with $16 \mathrm{~h}$ at $98^{\circ} \mathrm{or}$ r.h. and $8 \mathrm{~h}$ at $70 \%$ r.h. each day.

Treatment 4: received no leaf wetness and put into a controlled humidity chamber for 5 days with $16 \mathrm{~h}$ at $98 \%$ r.h. and $8 \mathrm{~h}$ at $70 \%$ r.h. each day.

Subsequently, the plants were transferred to a plant growth chamber $\left(26^{\circ} \mathrm{C}\right.$ and about $70 \%$
Table 1. Lesion density (number of lesions $/ \mathrm{cm}^{2}$ ) resulting from inoculation of groundnut leaves with dry Phaeoisariopsis personala conidia

\begin{tabular}{lcc}
\hline Treatment & $\begin{array}{c}\text { Lesion density } \\
\text { (lesions } / \mathrm{cm}^{2} \text { ) }\end{array}$ & $\begin{array}{c}\text { Conidial } \\
\text { germination } \\
(\%)\end{array}$ \\
\hline 1 Control & $7 \cdot 20$ & 90 \\
$295 / 70 \%$ r.h. & 0.07 & 84 \\
$398 / 70 \%$ r.h. & $0 \cdot 10$ & 88 \\
$498 / 70 \%$ r.h. & 0.00 & 0 \\
\hline
\end{tabular}

Conidial germination was assessed at the end of the treatment period ( 5 days after inoculation). Treatments 1-3 were placed in a dew chamber for $16 \mathrm{~h}$ to provide leaf wetness immediately after inoculation and treatment 4 received no leaf wetness but was put into a humidity chamber at $98 \%$ r.h. for the first $16 \mathrm{~h}$. Other details of treatments are given in the text.

r.h.) and observed for $\mathbf{2 0}$ days to assess disease development on a single leaf (four leafiets). Leaf areas were measured with a leaf area meter (Model 3100, LI-COR, Lincoln, NE, USA). Five days after inoculation, one leaf from each treatment was examined to assess percentage conidial germination. For this, leaflets were separated and cleared by soaking in acetic acid and alcohol $(3: 1)$ for $24 \mathrm{~h}$, then washed twice in distilled water, immersed in lactophenol cotton blue for $1 \mathrm{~h}$ and mounted in glycerine on a microscope slide (Wadia \& Butler, 1994b). Twenty-five conidia were observed on each of the four leaflets for each treatment. As no conidia germinated in treatment 4 , this experiment was not repeated.

In the second experiment, leaves were inoculated with an aqueous suspension of $10^{4}$ conidia/ml (Wadia \& Butler, 1994b) and plants from all treatments were placed in the dew chamber at $23^{\circ} \mathrm{C}$ for $16 \mathrm{~h}$ immediately after inoculation. This ensured sufficient leaf wetness to allow conidial germination but would not have provided sufficient time for host penetration by germ tubes, except for rare penetrations (Wadia \& Butler, 1994b).

After the initial wet period, the five treatments (Table 2) were as follows:

Treatment 1 (control) was the same as in the first experiment.

Treatment 2: put into controlled humidity chambers for 4 days with $16 \mathrm{~h}$ at $100 \%$ r.h. and 8 h at $80 \%$ r.h. each day. 
Table 2. Lesion density (number of lesions $/ \mathrm{cm}^{2}$ ) resulting from inoculation of groundnut leaves with a suspension of Phaeoisariopsis personata conidia

\begin{tabular}{lcc}
\hline Treatment & $\begin{array}{c}\text { Lesion density } \\
\text { (lesions/cm }\end{array}$ & $\begin{array}{c}\text { Conidial } \\
\text { germination } \\
(\%)\end{array}$ \\
\hline 1 Control & $7.31 \pm 0.91$ & 90 \\
2 100/80\% r.h. & $3.50 \pm 0.39$ & 83 \\
3 98/80\% r.h. & $0.35 \pm 0.08$ & 76 \\
$4100 / 100 \%$ r.h. & $1.40 \pm 0.84$ & 77 \\
5 Glasshouse & $0.15 \pm 0.02$ & 79 \\
\hline
\end{tabular}

Conidial germination was assessed at the end of the treatment period ( 5 days after inoculation). All treatments were placed in a dew chamber for $16 \mathrm{~h}$ to provide leaf wetness immediately after inoculation. Details are given in the text. Standard errors of lesion densities are given.

Treatment 3: put into controlled humidity chambers for 4 days with $16 \mathrm{~h}$ at $100 \%$ r.h. and $8 \mathrm{~h}$ at $80 \%$ r.h. each day.

Treatment 4: put into a humidity chamber with continuous $100 \%$ r.h.

Treatment 5: put into a glasshouse where daytime humidity was $40-50 \%$ r.h. The experiment was repeated to provide two replications and, as very similar results were obtained, both sets of data were pooled.

Leaves were sampled and cleared for microscopic examination at the end of the initial 16-h wetness period and subsequently at 24 -h intervals. Percentage germination, numbers of germ tubes, germ tube branches and host penetrations were counted for 50 randomly selected conidia in each treatment.

\section{Results}

Following dry inoculation in the first experiment, lesions only formed if a period of leaf wetness was provided to allow conidial germination. No conidia germinated at $98 \%$ r.h. without leaf wetness (Table 1). After $16 \mathrm{~h}$ leaf wetness, very few lesions formed with $95 / 70 \%$ and $98 / 70 \%$ r.h. regimes, despite greater than $80 \%$ conidial germination.

After an initial 16-h wetness period in the second experiment, there were significantly $(P<0.02)$ more lesions with the $100 / 80 \%$ r.h. regime than the $98 / 80 \%$ r.h. regime (Table 2 ). Comparing these treatments, the numbers of germ tubes and germ tube branches were only slightly reduced with $98 / 80 \%$ r.h. and the difference was not statistically different (Fig. 7a, b). However, there were substantial reductions in the number of host penetrations (Fig. 7c, d), significant at $P<0.05$ for germ tubes and $P<0.01$ for germ tube branches.

\section{DISCUSSION}

Stable humidity values were achieved by using proportional control to regulate the supply of dry air to the plant chambers and by working in a temperature stable environment. Humidity control is most difficult close to saturation (>95\% r.h.) and for this it was necessary to raise the dew-point temperature of the wet air supply slightly above the chamber temperature. This necessitated heating the wet air supply tubes to avoid condensation.

The system provided sufficiently precise control of humidity to avoid completely condensation of water on leaves up to $98 \%$ r.h. At $100 \%$ r.h., however, condensed water was inevitable, although the film may have been transient and was not always visible.

During each operation, special care was necessary to ensure that each chamber was completely sealed, particularly around the plant stem. Even a small leak would stop or reduce the flow of air to the humidity sensor and either give an erroneous reading or increase the response time of the system.

In general, the humidity control was better for chambers with a condensation dew-point meter than with a thin-film capacitative Humicap sensor. This was partly because the dew-point meter responded more rapidly than the Humicap sensor to changes in humidity. Repeated comparisons between Humicap sensors and a dewpoint meter often indicated a small drift in the Humicap reading (usually less than $1 \%$ r.h.) Therefore, in experiments comparing small differences in r.h., daily calibration checks of the Humicap sensors were necessary.

The actual short-term variation of r.h. in the plant chambers may be more than indicated in Fig. 4 because variations in the measured values depend on the response time of the humidity sensors. However, similar frequency distributions were found with both the dew-point meter and Humicap sensor. Because of the uncertainty in the extent of short-term humidity fluctuations. we allowed a safety margin in concluding that leaves would remain dry with a set value of $98 \%$ r.h. In addition there may be some spatial 

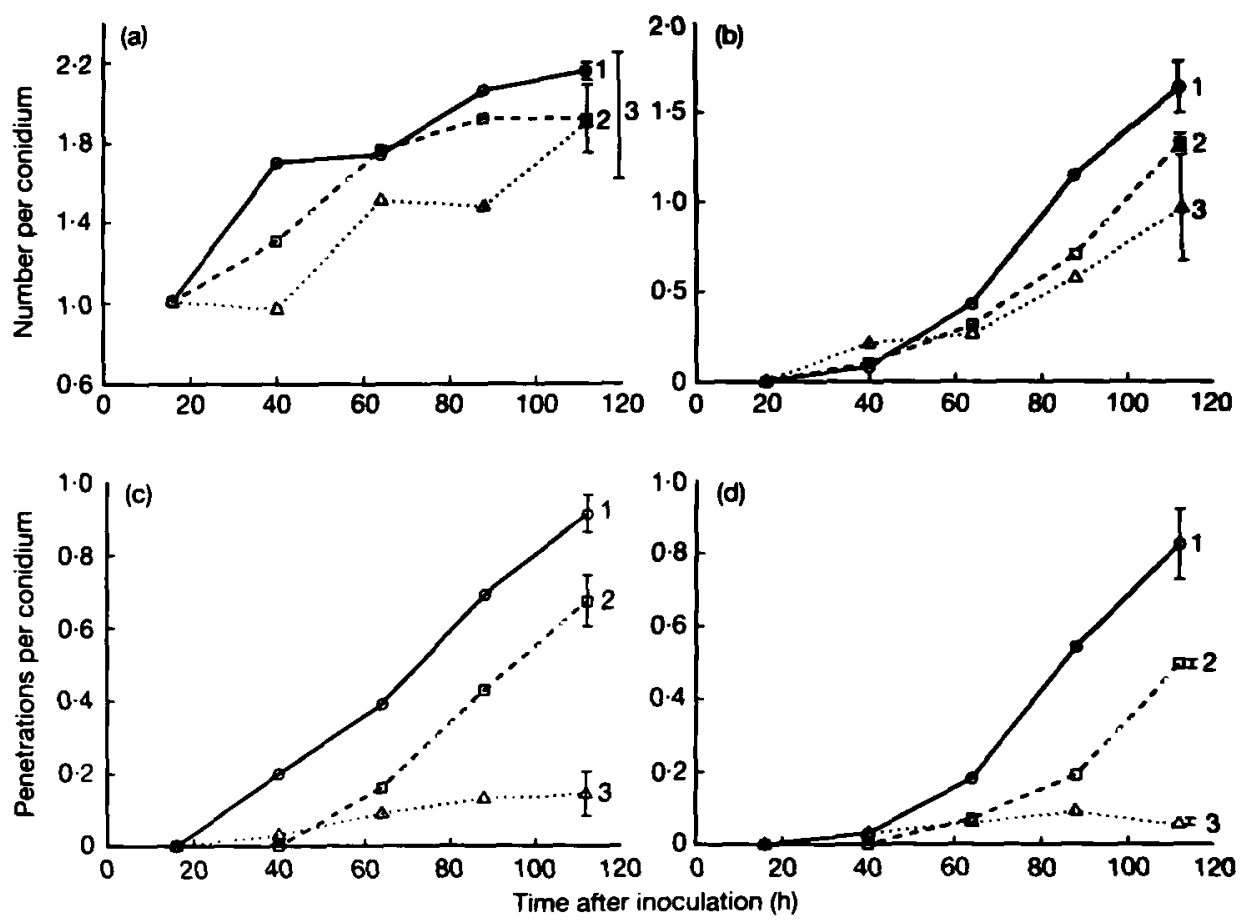

Fig. 7. Changes in (a) germ tube numbers; (b) germ tube branch numbers; (c) germ tube penetrations; (d) germ tube branch penetrations, after inoculating groundnut leaves with Phaeoisariopsis personata $\left(10^{4}\right.$ conidia/ml). Standard errors of the final values are indicated by bars labelled with the treatment numbers from the second experiment. Key: $-\mathrm{O}-$ dew chamber control; - - - - - $100 / 80 \%$ r.h.; $\cdots \Delta \cdots 98 / 80 \%$ r.h. All treatments received $16 \mathrm{~h}$ leaf wetness to ensure conidial germination.

variation in r.h. within the chamber, but this would be small because the air was thoroughly mixed by the fan. Air flow measurements (Model 8460 Air Velocity Transducer, TSI Inc., St Paul, MN USA) within a chamber varied between $0.4 \mathrm{~m} / \mathrm{s}$ and $2.3 \mathrm{~m} / \mathrm{s}$.

The results in Table 1 indicate that surface wetness was necessary for germination of $P$. personata conidia. After the conidia had germinated however, additional germ tubes emerged and germ tube branches grew with $98 \%$ r.h. when the leaf surface remained dry. With the $100 / 80 \%$ r.h. regime (when condensation is possible) about $30-40 \%$ of the germ tubes and branches penetrated the host, compared with less than $10 \%$ with $98 / 80 \%$ r.h. (Fig. 7 ).

It is clear that leaf wetness rather than high r.h. alone is necessary for substantial infection by $P$. personasa, and appears to be essential for conidial germination and promotion of host penetration by the pathogen.

\section{ACKNOWLEDGEMENT}

This paper was submitted as Journal Article No. 1604 from the International Crops Research Institute for the Semi-Arid Tropics (ICRISAT).

\section{REFERENCES}

Broughton WJ. Dilworth MJ, 1971. Control of leghaemoglobin synthesis in snake beans. Biochemistry Journal 25, 1075-80.

Butler DR, Wadia KDR, Jadhav DR. 1994. Effocts of leaf wetness and temperature on late leaf spor infection of groundnut. Plant Pathology 43, 112-20.

Clayton CN, 1942. The germination of fungal spores in relation to controlled humidity. Phyropolbolosi 32. $921-43$.

Harrison JG. 1992. Effects of the aerial environmeat on late blight of polato foliage-a review. Font Pathologv 41, 384-416.

Herrison JG, Lowe R, 1989. Efrects of hurnidity and air speed on sporulation of Phyramintone infesters on potato leaves. Plow Pathatery 34, 585-91. 
Lannou C, Blizoua Bi P, 1989. Conditions for the development of $C$. personatum leaf lesions on groundnut after artificial infection. Oléagineux 44, 531-5.

Lowe PR, 1976. An approximating polynomial for computation of saturation vapour pressure. Journal of Applied Meteorology 16, 100-3.

O'Brien FEM, 1948. The control of humidity by saturated salt solutions. Journal of Scientific Instruments 25, 73-6.

Schein RD, 1964. Comments on the moisture requirements of fungus germination. Phytopathology 54, 1427.
Wadia KDR, Butler DR, 1994a. Relationships between temperature and latent periods of rust and leaf spot diseases of groundnut. Plant Pathology 43, 121-9.

Wadia KDR, Butler DR, 1994b. Infection efficiency of Phaeoisariopsis personata and the influence of different wetness patterns on germ tube growth of the pathogen. Plant Pathology 43, 802-12.

Yarwood CE, 1978. Water and the infection process. In: Kozlowski TT, ed. Water Deficits and Plant Growth. Vol. 5. New York, USA: Academic Press, 141-73. 
This document is a scanned copy of a printed document. No warranty is given about the accuracy of the copy. Users should refer to the original published version of the material. 